\title{
Pro tip: Screen-based payment methods increase negative feelings in consumers but do not increase tip sizes
}

\author{
Francine W. Goh ${ }^{1}$, Alexandria C. Jungck ${ }^{1}, \&$ Jeffrey R. Stevens ${ }^{1}$ \\ ${ }^{1}$ University of Nebraska-Lincoln
}

\begin{abstract}
Leaving monetary tips for servers is a commonplace occurrence in the United States. Tipping research has proposed that consumers tip to serve a variety of motives such as to ensure good service on future patronage, supplement servers' wages, and comply with social norms. Meanwhile, research on environmental factors that affect tipping behavior, such as method of bill payment, have yielded mixed findings. The advancement of technology has increased the use of screen-based payment methods that feature options with differing suggested tip amounts. This technology may pressure consumers into leaving larger tips or start tipping in situations where they previously would not. Using a computer-based study, we simulated limited-service experiences where customers have short interactions with their servers (e.g., ordering a cup of coffee to-go at a coffee shop). We studied how the availability of screen-based payment methods affected consumer feelings about establishments and tip amounts. Results indicated that, in our simulated coffee shop scenario, people feel negatively about screen-based payment methods and may avoid limited-service establishments that use them, but they did not leave larger tips when compared to other payment methods. Moreover, people did not tip more when a server was visible (versus absent) and empathy did not moderate this effect. Together, these findings suggest that people tip to comply with social norms in limited-service environments even if they may feel negatively about the consumer experience.
\end{abstract}

Keywords: consumer behavior, payment methods, social norms, tipping Word count: 8961

Imagine arriving at your favorite café for your weekly visit and ordering your regular beverage. After ringing up your order, the barista swings a tablet around for you to sign off on the transaction. As the barista is watching, a screen appears asking you how much you want to tip. You've never tipped before in this café. How would you feel having this new suggestion? Would you offer a tip? If the barista was not watching you, would this change how you felt or your willingness to tip? Electronic tip screens are becoming more common in establishments that previously did not have this kind of technology. Our study aimed to investigate how tip screens and the presence of a service worker influence tipping behavior and perceptions of establishments that use these technologies.

Numerous factors influence whether and how much customers

Version: 2021-09-04

Department of Psychology, Center for Brain, Biology and Behavior, University of Nebraska-Lincoln, Lincoln, Nebraska, USA.

We thank Elise Thayer and London Wolff for comments on a previous draft.

Correspondence concerning this article should be addressed to Jeffrey R. Stevens, B83 East Stadium, University of NebraskaLincoln, Lincoln, Nebraska, 68588. E-mail: jeffrey.r.stevens@gma il.com tip (Lynn \& McCall, 2016), including environmental factors such as colors used in a restaurant's atmosphere, server physical attractiveness, and method of bill payment (Lynn \& Latané, 1984; Lynn \& Mynier, 1993; McCall \& Belmont, 1996; Guéguen \& Jacob, 2012, 2014; Lee et al., 2018). Lynn (2015a) conducted a review of the tipping literature and suggested a motivational framework for why people tip. This motivational framework posits that in general, people tip to fulfill five motives: to ensure continued good service, to gain social approval, to fulfill a sense of duty, to help their servers, and to reward service. With regard to the motive of ensuring continued good service on future visits, people self-report that they tip to gain high quality service for future visits and that they tend to leave larger tips at establishments they frequently patronize (Lynn \& Grassman, 1990; Lynn \& McCall, 2000; Conlin et al., 2003; Lynn, 2009). Other studies, however, report that the effect of repeated patronage of an establishment on tip size is weak, difficult to attribute solely to frequent patronage, or simply non-existent (Lynn \& McCall, 2000; Conlin et al., 2003; Azar, 2007a). When coupled with the fact that people tip even when they do not expect future interactions with their server (e.g., when people dine at an out-of-town restaurant), the notion that people tip solely to ensure quality future service is an insufficient explanation for why people may be motivated to tip since doing so will not benefit them. Instead, a more plausible explanation for why people may be motivated to tip is to adhere to the social norm. 
People conform to social norms to match the social expectations of others around them (Deutsch \& Gerard, 1955). Researchers have theorized that people tip to gain social approval from others and out of obligations that stem from these internalized tipping norms (Lynn \& Grassman, 1990; Lynn et al., 1993; Bodvarsson \& Gibson, 1997; Azar, 2007b; Whaley et al., 2014; Lynn, 2015a). Support for tipping to adhere to social norms has been reflected in surveys eliciting people's motivations to tip. These surveys found that respondents agreed with statements that explicitly state that they tip to follow social norms and that this finding is consistent across people from different ethnic groups and nationalities (Lynn, 2009, 2011; Azar, 2010; Saunders \& Lynn, 2010; Futrell, 2015). One possible reason why people comply with tipping norms is to avoid negative feelings (e.g., embarrassment and guilt) that result from not complying with these norms (Bodvarsson \& Gibson, 1997; Azar, 2004, 2007b; Parrett, 2006; Lynn, 2015b). This notion has been supported by surveys that found respondents agreed with statements that reflect tipping to avoid the experience of negative feelings (Parrett, 2006; Lynn, 2009; Azar, 2010; Futrell, 2015).

Further, previous work on tipping behavior has largely been conducted in the context of full-service restaurants that provide table service where customers interact with their server over a prolonged period. Less is known about how tipping behavior differs in the context of limited-service establishments that utilize counter service (e.g., coffee shops, food kiosks, and bars) where customers typically have fleeting interactions with their server and have to tip before receiving service. Though limited, studies have found that tip requests at such establishments can result in increased customer irritation that lead to smaller tip sizes and lower intention to patronize the establishment in future (Karabas et al., 2020; Warren et al., 2020). Specifically, Karabas et al. (2020) found that participants who were presented with a tip request (compared to those who were not) indicated irritation with the establishment and subsequent lower likelihood to patronize the establishment in future, while Warren et al. (2020) found that presenting a preservice tip request led to smaller tip sizes and lower likelihood to return to the establishment because customers feel manipulated by the establishment. However, Lynn (2009) and Azar (2010) found in their surveys that respondents indicated their motivation to follow social norms-and thus to gain social approval-was stronger compared to their motivation to avoid negative feelings from not tipping. Collectively, these findings suggest that people tip to serve several motives at a time, which aligns with Azar's (2004) proposition that, though people tip to follow social norms, they may also do so because of other reasons such as empathy for servers who may earn lower wages compared to themselves.

People may decide to tip servers to help supplement their low wages and reward service (Azar, 2004, 2010; Lynn, 2009, 2015b, 2019; Saunders \& Lynn, 2010). In particular, empathy has been proposed to moderate this motivation to tip because individuals high in empathy are expected to be able to take the perspective of others with ease (Waal, 2008; Iacoboni, 2009; Davis et al., 2017). Indeed, studies on tipping behavior have shown that people who had experience working at tipreceiving jobs tended to leave larger tips than those who did not have similar work experiences (Parrett, 2011; Lynn et al., 2012). Moreover, other studies have found that empathy manipulated via the activation of prosocial primes (e.g., listening to songs that contain prosocial lyrics) led to increases in tendency to tip and larger tip sizes (Jacob et al., 2010, 2013). When considered together with the pressure to adhere to social norms, the desire to supplement server wages because one empathizes with their server could help explain why tipping is still a prevalent practice in society.

\section{Effect of bill payment method on tipping behavior}

Besides individual motivations to tip, environmental factors such as method of bill payment may affect tipping decisions. Though one might expect that method of payment (credit card or cash) may influence tip size, existing studies have yielded mixed findings. While some studies have found that the use of a credit card payment method results in greater tip sizes compared to a cash payment method (Lynn \& Latané, 1984; Lynn \& Mynier, 1993), others have found no difference in tip sizes between the two payment methods (Parrett, 2006; Bluvstein Netter \& Raghubir, 2021). Additionally, the continuous advancement of technology has offered establishments in the food and beverage industry the option of mobile payment methods for sale transactions. Mobile point-of-sale systems that utilize electronic tablets such as iPads have become ubiquitous with establishments that wish to remain relevant in an increasingly digital society (Taylor, 2016). Such payment methods typically provide customers with tip screens that feature suggested tip amount options calculated based on their bill size, which has in turn been suggested to cause customers to feel obligated to leave a tip or tip amounts larger than they would otherwise prefer (Kim, 2018; Levitz, 2018). In other words, customers may feel pressured to tip their server, resulting in potentially greater tips for servers in the short-term but also greater negative feelings from customers towards the establishment in the long-term. Thus, it remains to be seen whether differences in payment method affects tip sizes in the context of limited-service establishments. Taken together with the fact that limited-service establishments frequently make use of mobile point-of-sale systems that provide suggested tip amount options, the interplay between the potential added pressure to tip via a tip screen payment method and the context of a limited customer-server interaction on tipping behavior remains to be explored. 


\section{Overview of current studies}

To investigate the effect of the tip screen payment method on tipping behavior, we conducted two studies, where Study 1 was a within-subjects design run in the laboratory and Study 2 was a between-subjects design conducted online. For both studies, we created a computer-based simulation of a coffee house where customers order their beverages from a barista at a counter. First, we hypothesized that people would have more negative feelings towards establishments that utilize a tip screen compared to establishments that utilize a tip jar for tip solicitation due to increased pressure to tip. A corollary hypothesis was that people would indicate greater avoidance of establishments that utilize tip screens instead of tip jars because they want to avoid the negative feelings associated with tip screens. Third, payment method was hypothesized to affect tip size, with tips made via a tip screen being larger than tips made via other payment methods due to the nudging effects of tip amount suggestions. In addition to investigating the effects of a tip screen payment method on tip size, a secondary goal of the present study was to examine the effect of server presence on tip size. Specifically, we expected people to indicate larger tip sizes when an image of the barista was present compared to when absent. This hypothesis aligns with people behaving more generously when they had knowledge of subtle cues that their actions were being observed [e.g., an image of a pair of eyes; Haley and Fessler (2005); Bateson et al. (2006);Burnham and Hare (2007)] and with Shih et al. (2019)'s finding that creating a perception of social interaction via an image of a service worker encourages tipping. In a related vein, the effect of barista presence on tip size was hypothesized to be moderated by individual differences in empathy since empathetic individuals should be more sensitive to the presence of the barista compared to less empathetic individuals.

\section{Study 1}

The goal of Study 1 was to investigate the effects of payment method on tip size. We used a within-subjects study design to examine how people's tipping behavior changed across different tipping scenarios where the type of payment method and server presence were varied.

\section{Method}

\section{Participants and procedures}

Participants were 236 undergraduates (177 women, 56 men, 3 unspecified; $\mathrm{M}_{\mathrm{age}}=19.32, \mathrm{SD}=1.77$ ) recruited through the undergraduate psychology study pool at the University of Nebraska-Lincoln from October to November 2017. The majority of participants were White (75\%; see Table S1 for detailed description). All participants received course credit and completed an informed consent form that was approved by the university Institutional Review Board prior to the start of the study (protocol \#17100) and conforms to US Federal Policy for the Protection of Human Subjects.

Participants completed the study in a computer laboratory via Qualtrics Online Survey Software (https://qualtrics.com). To investigate the extent of the potential increased pressure to tip in a limited-service establishment, participants indicated their tip amounts for six conditions in which we varied the presence of a barista and payment method (Figure 1). After completing the tipping conditions, participants indicated their feelings towards establishments that utilize tip screens and tip jars and the extent to which they would go to avoid such establishments. Finally, participants completed an empathy scale and received research credit for their participation.

\section{Measures}

Tipping scenarios. Participants indicated their desired tip amounts for six tipping conditions. Each tipping condition consisted of a pairing between a barista condition (two levels) and payment method (three levels; Figure 1). For the barista condition, participants saw either an image of a barista standing in front of a cash register along with the total cost of a food item (barista present condition) or an image of a cash register with no barista (barista absent condition), along with the total cost of a food item. For payment method, participants saw one of three images: (1) a tip screen with suggested tip amounts (tip screen condition), (2) a receipt with empty tip and total amount fields (receipt condition), and (3) a tip jar filled with dollar bills (tip jar condition). For each tipping condition, participants were informed of the total cost of the food item before they either selected from a menu or manually entered their desired tip amount and were then directed to the next tipping condition. The order of tipping conditions was randomized for each participant to prevent the occurrence of question order effects.

Feelings towards tip screens and tip jars. Participants indicated the level of negativity they felt towards establishments that utilize tip screens and tip jars. Specifically, they responded to the question "Some food establishments use a tip screen [tip jar] to make it very easy for people to tip. How positive or negative does this make you feel?" on a Likerttype scale that featured seven options ranging from (1) "very positive" to (7) "very negative." Additionally, participants indicated how often they have consciously tried to avoid establishments that utilize tip screens and tip jars ("How often have you consciously tried to avoid or reduce exposure to a tip screen [tip jar]?") on a Likert-type scale ranging from (1) "never" to (5) "more than 10 times."

Individual differences in empathy. The emotional quotient scale (Lawrence et al., 2004) was used to measure participants' empathy. The scale contains 28 items that measure three factors of empathy: cognitive empathy, emotional empathy, and social skills. Participants rated the extent to which 
(a) Tip screen, barista present

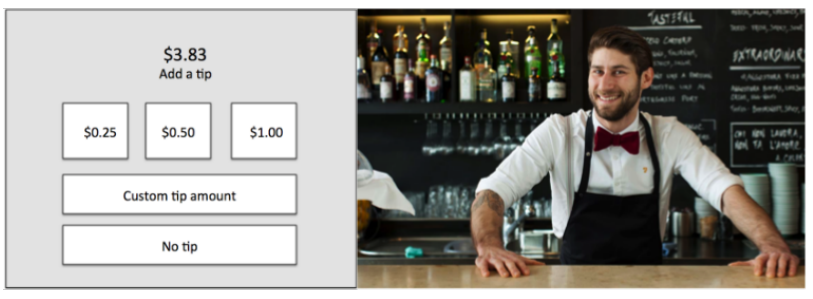

(c) Receipt, barista present

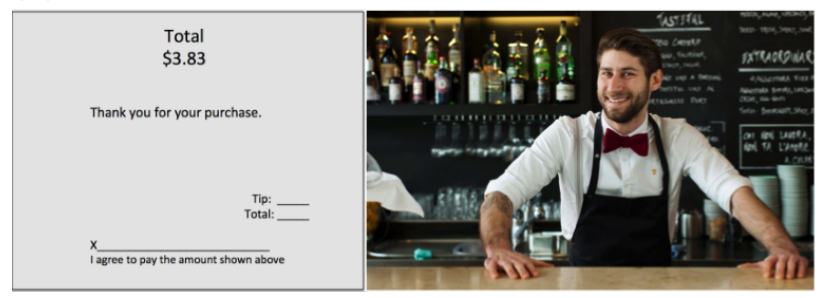

(e) Tip jar, barista present

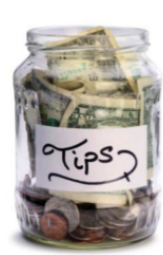

(b) Tip screen, barista absent

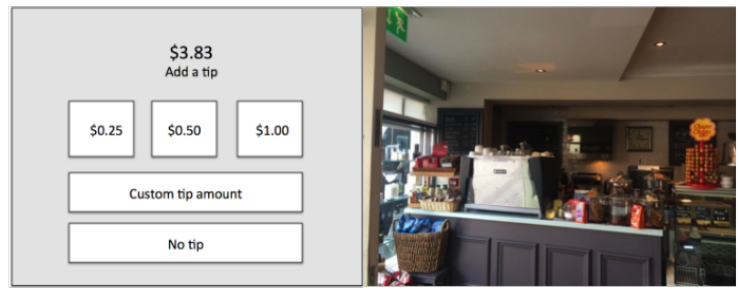

(d) Receipt, barista absent

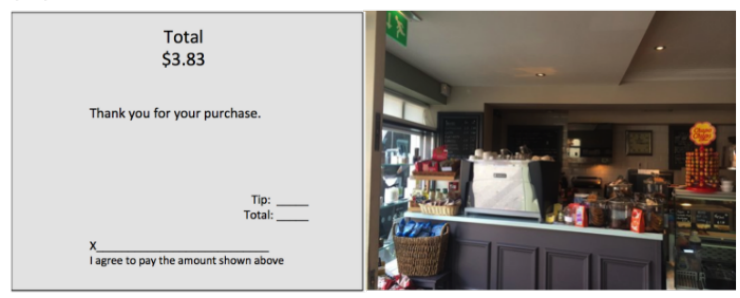

(f) Tip jar, barista absent

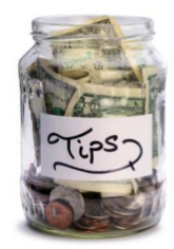

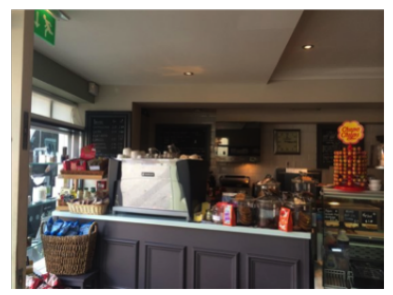

Figure 1. Screenshots of tipping scenarios. Participants observed six tipping scenarios in randomized order where the barista condition and payment method were varied before indicating their desired tip amount. The six scenarios were (a) tip screen, barista present condition, (b) tip screen, barista absent condition, (c) receipt, barista present condition, (d) receipt, barista absent condition, (e) tip jar, barista present condition, and (f) tip jar, barista absent condition. For each tipping scenario, participants read the following description: "Imagine you go to a coffeehouse,"The Grind", and order an item from the menu. Your item costs \$3.83." In the barista present scenarios, this description was followed by "[Once you pay for it with a credit card, you are prompted with a tip screen. OR You pay for it with a credit card. OR Once you pay for it with cash, you notice the tip jar on the counter in front of the barista.] The barista is waiting for you to pay so he can finish the transaction. How much do you tip?" In the barista absent scenarios, the sentence, "the barista is waiting for you to pay so he can finish the transaction," was replaced with "the barista has already begun helping another customer."

they agreed with each item on the emotional quotient scale (e.g., "I find it easy to put myself in somebody else's shoes.") on a Likert-type scale ranging from (1) "strongly disagree" to (7) "strongly agree." Reverse keyed items were reverse coded before scores on the scale were summed and averaged across the 28 items to provide participants with overall mean empathy scores with higher scores indicating a greater amount of empathy. This scale demonstrates strong reliability and validity with other measures of empathy (Lawrence et al., 2004; Groen et al., 2015).

\section{Data analysis}

Data were processed and analyzed using R [Version 4.1.1; R Core Team (2020)] and the R-packages BayesFactor [Version 0.9.12.4.2; Morey and Rouder (2018)], broom [Version
0.7.9; Robinson and Hayes (2020)], car [Version 3.0.11; Fox and Weisberg (2019)], here [Version 1.0.1; Müller (2017)], lme4 [Version 1.1.27.1; Bates et al. (2015)], lsr [Version 0.5; Navarro (2015)], moments [Version 0.14; Komsta and Novomestky (2015)], patchwork [Version 1.1.1; Pedersen (2019)], rptR [Version 0.9.22; Stoffel et al. (2017)], and tidyverse [Version 1.3.1; Wickham et al. (2019)]. We excluded participant responses from our analyses that were missing or at least three standard deviations above the mean tip size for our sample (following recommendations from Ratcliff, 1993) because the tipping literature has shown that people consistently tip around 15 to 20 percent of their total bill in the United States (e.g., Lynn et al., 2012; Lynn \& McCall, 2016). For mean empathy scores, we excluded participants from our analysis who did not complete the emotional quotient scale 
because this would have resulted in an inaccurate overall mean empathy score. Additionally, the distribution of tip amounts was positively skewed (absolute value $=0.57$ ) and platykurtic (absolute value $=1.72$ ). A square root transformation reduced the skew (absolute value $=0.05$ ) and only increased kurtosis slightly (absolute value $=1.42$ ). Thus, we conducted our analyses on the square root transformed data. Data and analysis scripts are available in Supplementary Materials and at the Open Science Framework (https://osf.io/bqf52/).

We conducted paired samples t-tests to investigate our hypotheses that participants would have more negative feelings towards establishments that utilize a tip screen compared to establishments that utilize a tip jar, and that participants would indicate greater avoidance of establishments that utilize tip screens instead of tip jars. In contrast, we used linear mixed effects models to test our hypotheses on the effects of payment method and barista presence on tip size, and empathy and barista presence on tip size. Linear mixed-effects modeling was warranted for the latter set of hypotheses to account for the non-independence in our data because participants repeatedly made decisions on how much to tip for their purchases whereas participants only had to indicate their response once for our feelings and avoidance questions (Peugh, 2010). We calculated the intraclass correlation (ICC) for participant tip amounts to check for this non-independence and our result yielded that $46.9 \%$ [95\% CI: 40.4, 52.6] of the variation in tip amounts was accounted for by differences among participants. This suggests that participants tipped differently from one another across the various tipping conditions, therefore justifying our use of a linear mixed-effects model for our analyses.

To find the best-fitting model for our data, we used a backward model selection procedure to first find the best-fitting random-effect structure, then tested the various fixed effects together with the random-effect structure. To investigate the effect of payment method and barista presence on tip size, we started with the full random-effect structure that included a random intercept for participants (to account for participants tipping multiple times) and random slopes for payment method and barista presence (to account for participants potentially experiencing the effects of both variables differently from each other). We then eliminated non-significant effects before using a nested model comparison (likelihood ratio test) to select the best-fitting random-effect structure. The full fixed-effect model was subsequently constructed by adding payment method, barista presence, and their interaction to the random-effect structure. Lastly, the final best-fitting model was selected using the same elimination and nested model comparison procedure used for the random effects. To investigate the effect of empathy and barista presence on tip size, we used the same backward model selection procedure as that for the effects of payment method and barista pres- ence, with the only difference being the inclusion of mean empathy score instead of payment method in the full fixedeffect model. All final models met assumptions of normally distributed residuals and homogeneity of variance.

In addition to frequentist statistics, we calculated Bayes factors $(B F)$ to assess the amount of evidence for the alternative hypothesis $\left(\mathrm{H}_{1}\right)$ relative to the null hypothesis $\left(\mathrm{H}_{0}\right)$. That is, Bayes factors are the ratio of evidence for $\mathrm{H}_{1}$ over evidence for $\mathrm{H}_{0}$ (Wagenmakers, 2007; Andraszewicz et al., 2015; Wagenmakers et al., 2016). Therefore, a Bayes factor of 3 indicates three times more evidence for $\mathrm{H}_{1}$ than $\mathrm{H}_{0}$, whereas a Bayes factor of $1 / 3$ (the reciprocal of 3 ) indicates 3 times more evidence for $\mathrm{H}_{0}$ than $\mathrm{H}_{1}$. We interpreted Bayes factors based on Wagenmakers et al. [(2018); see Table S2 for more detailed interpretations], where a $B F>3$ is sufficient evidence for the alternative hypothesis, $B F<1 / 3$ is sufficient evidence for the null hypothesis, and $1 / 3<B F<3$ indicate neither hypothesis has evidence supporting it (suggesting the sample size is too small to draw conclusions). Bayes factors for t-tests were calculated using the ttest $B F$ function from the BayesFactor R package (Morey et al., 2018) with the default settings for the priors, or expected beliefs about the data before analyses (default settings: Cauchy distributions for effect sizes and noninformative/uniform distributions for variance). For the linear models, we calculated Bayes factors by first extracting the Bayesian Information Criterion (BIC) for each fixed-effect model and the best-fitting random-effect model. We then inputted the BIC values into Wagenmakers' (2007) equation that converts BICs to BFs.

\section{Results}

Participants experienced six tipping conditions where the barista presence and payment method were varied (see Table $\mathrm{S} 3$ for descriptive information for tip sizes as a function of barista presence and payment method).

\section{Feelings towards tip screens and tip jars}

Results from a paired samples t-test revealed that participants had greater negative feelings towards establishments that utilize tip screens compared to those that utilize tip jars $\left(M_{d}=-0.30,95 \%\right.$ CI $[-0.49,-0.11], t(230)=-3.16$, $p=.002, \mathrm{BF}_{10}=9.19$, Cohen's $d=0.25$; Figure 2a). Additionally, participants reported avoiding establishments that utilize tip screens more frequently compared to those that utilize tip jars $\left(M_{d}=-0.27,95 \%\right.$ CI $[-0.46,-0.08], t(229)=-2.76$, $p=.006, \mathrm{BF}_{10}=2.97$, Cohen's $d=0.21$; Figure 2b).

\section{Effect of payment method and barista presence on tip- ping behavior}

We investigated whether payment method and barista presence impacted tipping behavior by measuring participants' tip sizes 
(a)

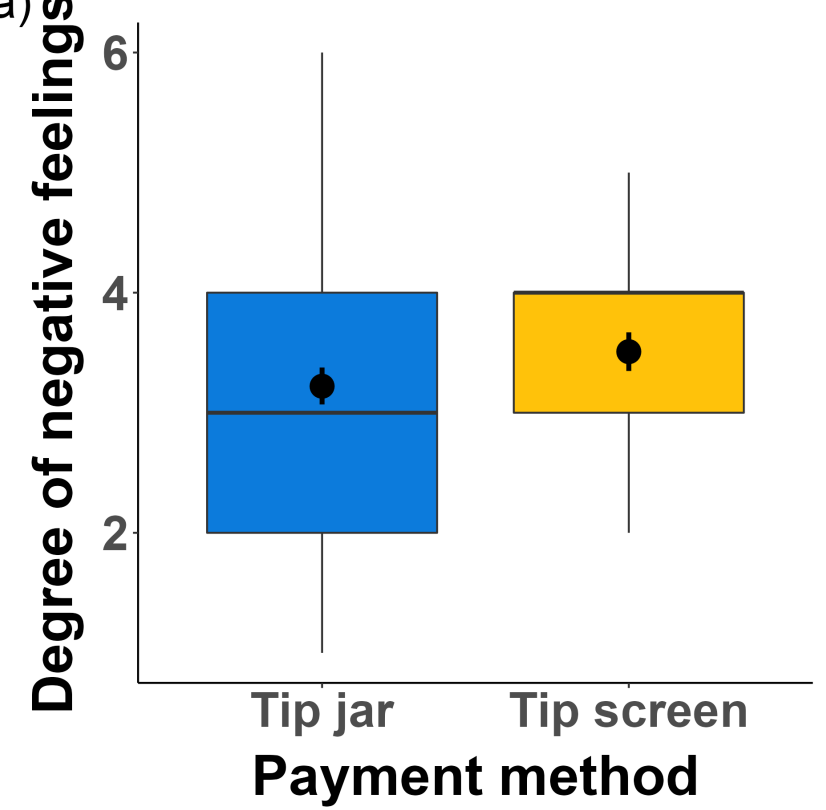

(b)

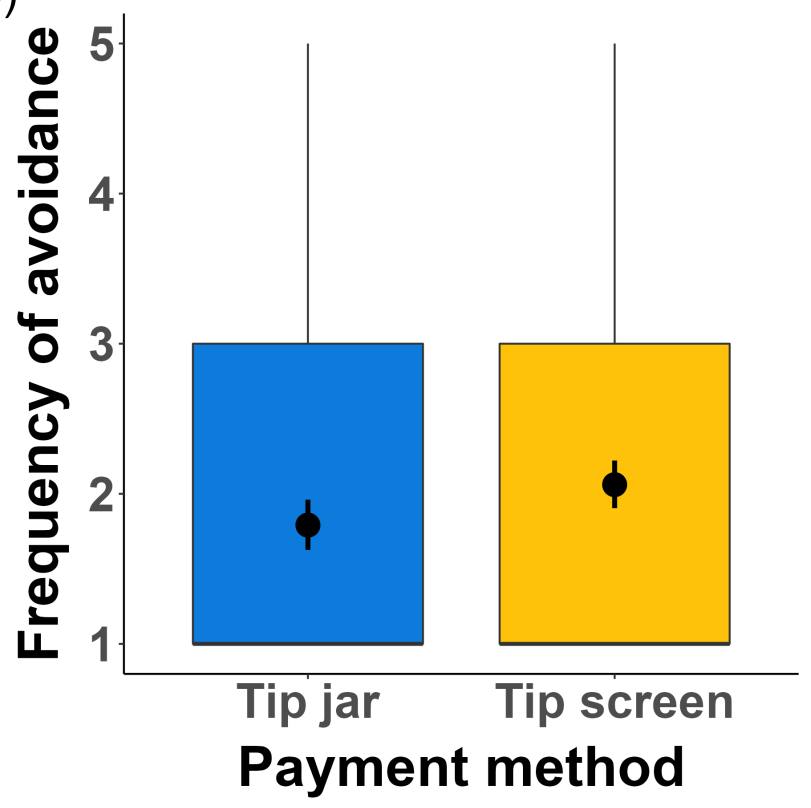

Figure 2. (a) Degree of negative feelings participants have towards establishments that utilize tip screens and tip jars in Study 1. (b) Frequency of participant avoidance of establishments that utilize tip screens and tip jars in Study 1. Frequency ratings are as follows: 1 = "never," 2 = "once," 3 = "2-5 times," 4 = "6-10 times," and $5=$ "more than 10 times." Dots and error bars represent mean values and 95\% within-subject confidence intervals respectively. For boxplots, horizontal bars represent medians, boxes represent interquartile ranges $\left(25^{\text {th }}-75^{\text {th }}\right.$ percentile), whiskers represent 1.5 times the interquartile range. Outliers are not shown..

across tipping conditions. Results from our model testing revealed that the best-fitting random effect structure included both a random intercept for each participant to account for tip differences within participants across tipping conditions and random slopes for payment method and barista presence to account for participants experiencing these effects differently from each other (random intercept model for participant with versus without random slopes: $\left.\chi^{2}(3)=44.09, p=<.001\right)$. The inclusion of the fixed effects of barista presence $\left(\chi^{2}(1)=\right.$ $\left.60.14, p=<.001, \mathrm{BF}_{10}>100\right)$ and the interaction between barista presence and payment method $\left(\chi^{2}(3)=60.71, p=\right.$ $\left.<.001, \mathrm{BF}_{10}>100\right)$ improved the fit of the empty random effect model. In contrast, the inclusion of payment method did not improve the fit of the empty random effect model $\left(\mathrm{BF}_{10}<0.01\right.$; Table S4). To ensure the accuracy of our model testing results, we tested the effect of payment method and barista presence on tip size using a $3 \times 2$ within-subjects ANOVA; these results yielded the same findings as those of our linear mixed modeling analyses (see Table S6 for detailed results). Thus, participants' tipping behavior did not significantly vary across payment methods when they had to leave a tip using tip screens, receipts, or cash, contradicting our prediction that tips made via tip screens would be larger than tips made via other payment methods (Figure 3a). Yet, participants tipped $\$ 0.14$ more on average when a barista was present compared to when a barista was absent, thereby supporting our prediction that an image depicting a server present would yield larger tip sizes compared to one with no server (Figure 3b).

Though the present study's within-subjects design allowed us to analyze how participants' tipping behaviors changed across different tipping scenarios, within-subjects designs can result in participants experiencing carry over effects due to repeated exposure to study scenarios that subsequently lead to artificial question responses. To address this possibility, we tested the robustness of our findings by conducting our analysis using only data from the first tipping condition that participants experienced during the study. This in essence created a betweensubjects study design as participants would have only seen a single tipping condition. The results of our linear modeling analyses revealed that participants did not significantly differ in the amounts that they tipped when the variables of payment type $\left(F(2,224)=1.44, p=.239, \mathrm{BF}_{10}=0.17\right.$; Figure $\left.3 \mathrm{c}\right)$ and barista presence $\left(F(1,225)=0.27, p=.601, \mathrm{BF}_{10}=0.17\right.$; Figure 3d) were varied, suggesting that our within-subjects study design may have imposed demand characteristics and elicited artificial responses from participants. Again, we conducted a $3 \times 2$ between subjects ANOVA to test the accuracy of our analyses and found that these results yielded the same 
findings as those of our linear modeling analyses (see Table S7 for detailed results).

\section{Effect of empathy on barista presence}

We investigated how empathy moderated the effect of barista presence on tip size by examining participants' mean empathy scores and their tip sizes (Figure 4a). The best-fitting random effect structure included only a random intercept for each participant to account for tip differences within participants across tipping conditions (against a null model with no random effects: $\left.\chi^{2}(1)=123.24, p=<.001\right)$. Separately, the inclusion of the fixed effect of barista presence to the model $\left(\chi^{2}(1)=56.06, p=<.001, \mathrm{BF}_{10}>100\right)$ and both barista presence and empathy to the model $\left(\chi^{2}(1)=56.06, p=<\right.$ $\left..001, \mathrm{BF}_{10}>100\right)$ improved the fit of the empty random effect model (Table S5). However, since the less complex model that included only the fixed effect of barista presence provided an equally good fit as that of the model with both barista presence and empathy $\left(\chi^{2}(1)=1.89, p=.169, \mathrm{BF}_{10}=0.12\right)$, we conclude that the addition of empathy did not improve the fit of the empty random effect model. We again conducted a simulated between-subjects analysis using the same method as that for the effects of payment method and barista presence on tip size. The results of this analysis replicated the finding that empathy did not affect tip size $(F(3,223)=0.20, p=.898$, $\mathrm{BF}_{10}=0.17$; Figure $4 \mathrm{~b}$ ). Collectively, these results suggest that, contrary to our hypothesis, empathy did not moderate the effect of barista presence on tip size. Additionally, we examined the effect of empathy on tip size since previous studies have reported that empathy increased tip sizes. Results of this exploratory analysis showed that empathy level did not moderate tip size $\left(t(211)=-1.37, p=0.17, \mathrm{BF}_{10}=0.12\right)$.

\section{Discussion}

The present study examined the effects of payment method on tipping behavior. We found that participants indicated greater negative feelings towards establishments that use tip screens and reported avoiding such establishments more often compared to those that use tip jars. Yet, payment method did not influence tip size, suggesting that the provision of recommended tip amounts was insufficient in nudging participants to leave bigger tips. In contrast, the presence of a barista appeared to be powerful enough to prompt participants to leave larger tips and empathy did not moderate this effect on tipping behavior. However, a between-subjects analysis of the first condition encountered by participants failed to replicate this barista presence effect on tip sizes. This finding suggests that our within-subjects study design could have imposed demand characteristics on participants, leading to artificial differences in tip sizes between the barista presence conditions. Thus, we conducted a second, between-subjects study to further investigate the effects of payment method and barista presence on tip size.

\section{Study 2}

The goal of the present study was to replicate the results from Study 1 using a between-subjects study design. In this study, participants experienced only one tipping scenario. Additionally, the present study was conducted in an online setting following social distancing guidelines issued during the ongoing COVID-19 pandemic at the time of data collection.

\section{Methods}

\section{Participants and procedures}

Participants comprised workers recruited from Amazon Mechanical Turk (MTurk) who were geographically located in the United States. To determine participant sample size, we used sequential hypothesis testing with Bayes factors (Rouder, 2014; Schönbrodt \& Wagenmakers, 2018). We calculated the Bayes factors for the effects of payment method and barista presence on tip size until we obtained sufficient evidence to support either the alternative or null hypothesis. To do this, we collected data from 50 participants and then checked if all relevant Bayes factors were $<1 / 3$ or $>3$. If they were not, we collected participants in batches of five until the thresholds were met. This occurred after testing 65 participants, but we had to exclude 5 participants based on their responses (see Data analysis), leaving 60 participants for data analysis (26 women, 34 men; $\mathrm{M}_{\mathrm{age}}=39.87, \mathrm{SD}=13.10$ ). Participants completed the study in September 2020 and the majority of participants were White (68\%; see Table S1 for detailed description).

Participants first viewed a brief description of the study on MTurk and decided if they wanted to participate in the study. To implement a between-subjects study design, participants were randomly assigned to one of the six tipping conditions identical to those in Study 1 (Figure 1). The rest of the procedure was identical to that of Study 1, where participants selected or entered a tip amount, indicated their feelings towards establishments that utilize tip screens and tip jars and the extent to which they would go to avoid such establishments, and completed the empathy scale. Upon completion of the study, participants received monetary compensation of $\$ 1.50$ via their MTurk accounts for an average participation time of 14 minutes.

\section{Data analysis}

The present study occurred during the COVID-19 pandemic, which could influence people's tipping behavior. Notably, people may tip more than before the pandemic to help boost service workers' income. In fact, we recorded several unrealistically large tip amounts (e.g., an $\$ 80$ tip for a $\$ 3.83$ bill) compared to Study 1 . Therefore, we used the range of tip amounts obtained from Study 1 to restrict the acceptable amounts for this study. As a result, five participants with 
(a)

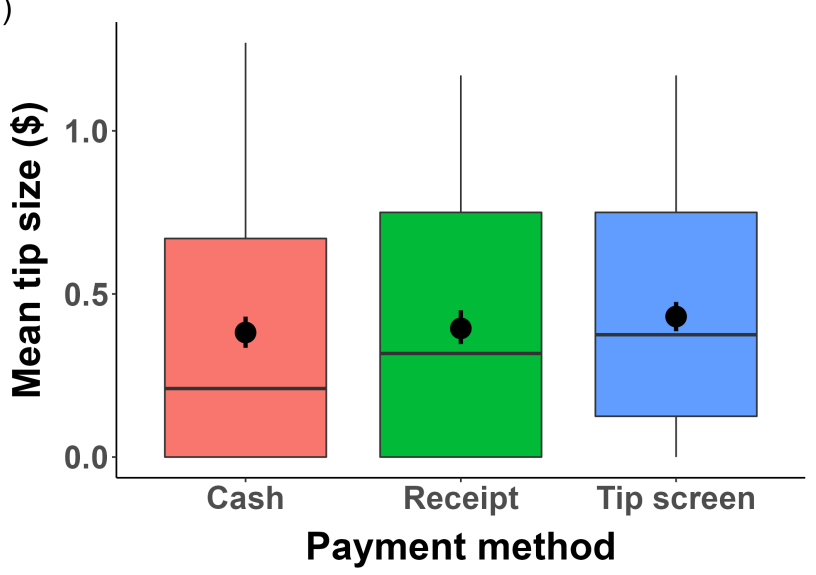

(c)

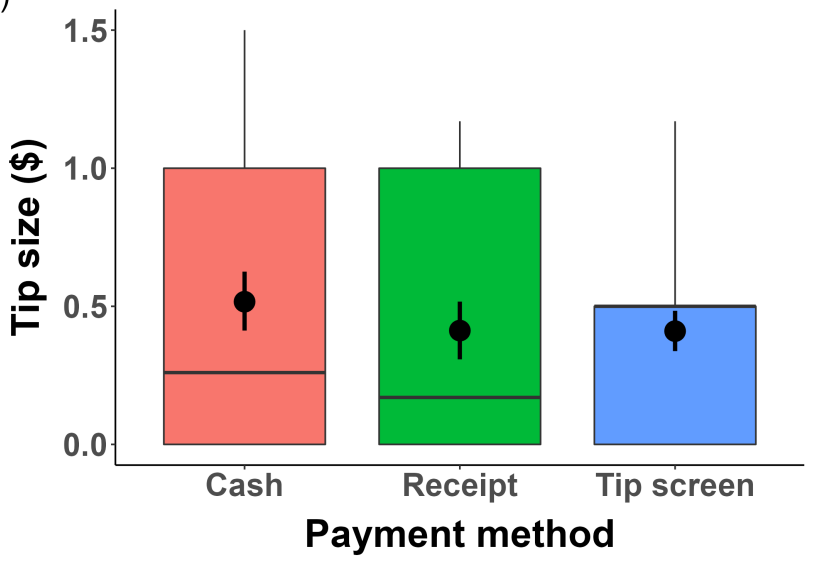

(b)

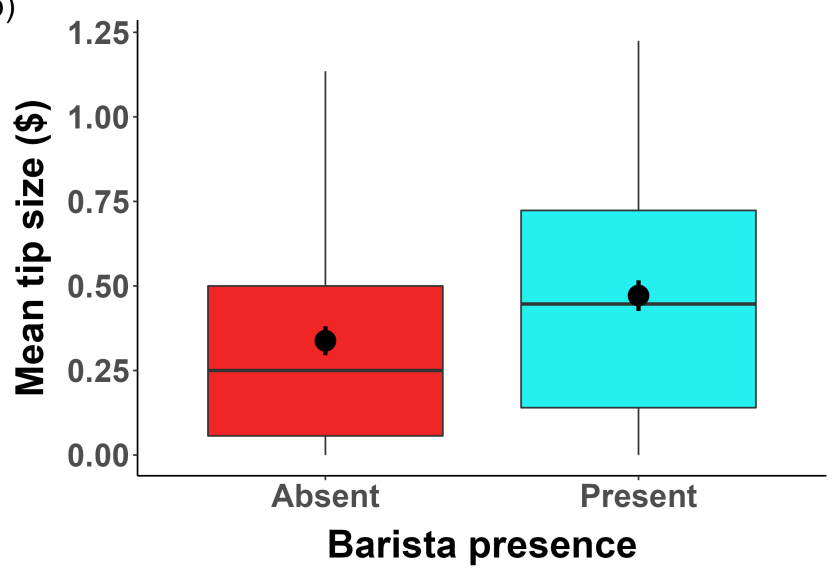

(d)

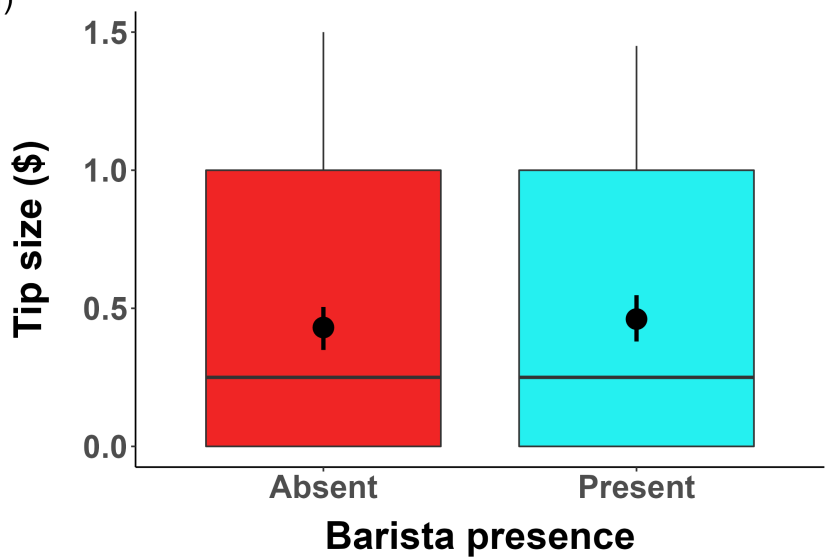

Figure 3. (a) Mean tip sizes indicated by participants for cash, receipt, and tip screen payment methods in Study 1. (b) Mean tip sizes indicated by participants for the barista absent and barista present conditions in Study 1. (c) Tip sizes indicated by participants for cash, receipt, and tip screen payment methods in the single tipping condition analysis for Study 1. (d) Tip sizes indicated by participants for the barista absent and barista present conditions in the single tipping condition analysis for Study 1. Dots and error bars represent mean values and 95\% within-subject (within-subject analyses) or between-subject (single tipping condition analyses) confidence intervals respectively. For boxplots, horizontal bars represent medians, boxes represent interquartile ranges $\left(25^{\text {th }}-75^{\text {th }}\right.$ percentile), whiskers represent 1.5 times the interquartile range. Outliers are not shown..

tip amounts outside of this range (greater than \$2) were excluded from the original sample size of 65 participants in our analyses. Additionally, the distribution of tip amounts was positively skewed (absolute value $=0.30$ ) and platykurtic $($ absolute value $=1.64)$.

Similar to Study 1, we conducted paired samples t-tests to investigate our hypotheses that participants would have more negative feelings towards establishments that utilize a tip screen compared to establishments that utilize a tip jar, and that participants would indicate greater avoidance of establishments that utilize tip screens instead of tip jars. We used linear regression models to test our hypotheses on the effects of payment method and barista presence on tip size, and empathy and barista presence on tip size. To investigate the fixed effects of payment method and barista presence on tip size, payment method and barista presence were entered into separate regression models to predict tip size. This was similar to the way we constructed the fixed-effect model in Study 1. Likewise, to investigate the effect of empathy and barista presence on tip size, we similarly used a regression model where we entered participant empathy score and barista presence to predict tip size. 
(a)

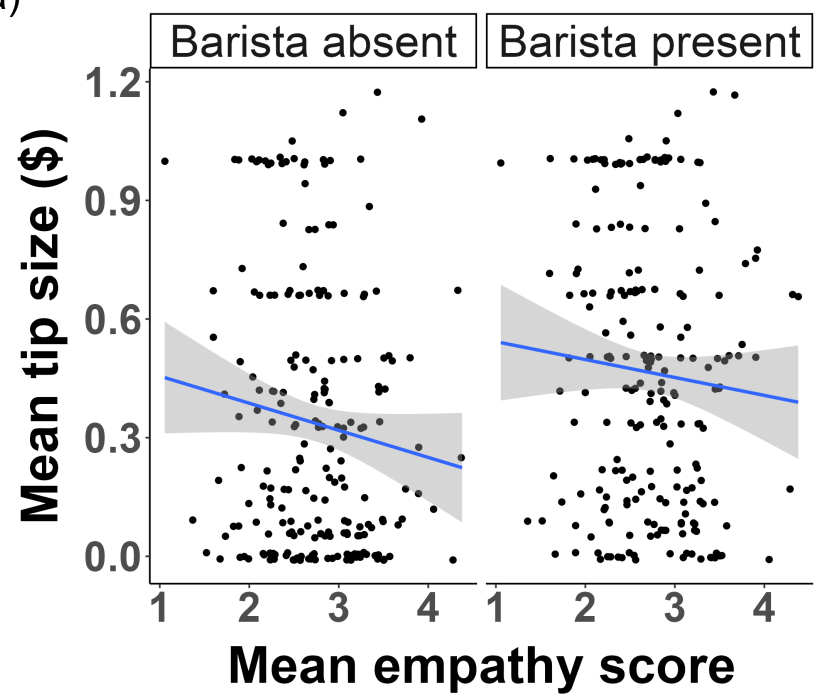

(b)

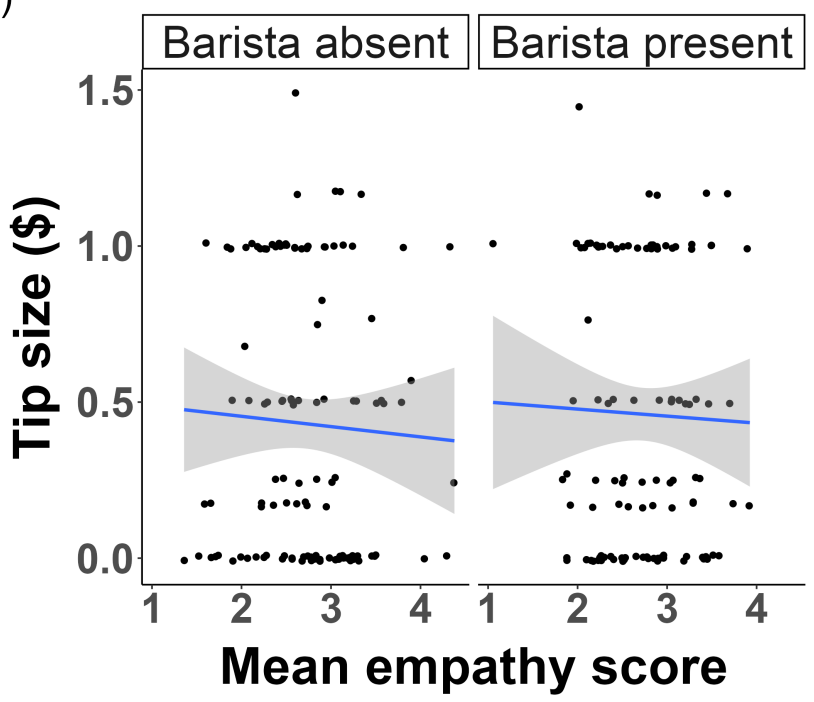

Figure 4. (a) Mean tip sizes indicated by participants for the barista absent and barista present conditions across empathy scores in the within-subjects analysis for Study 1 (higher scores mean more empathy). (b) Tip sizes indicated by participants for the barista absent and barista present conditions across empathy scores in the single tipping condition analysis for Study 1 ..

\section{Results}

Participants indicated their tip size for a tipping scenario that featured either a barista present or absent together with one of three payment methods (see Table S3 for descriptive information for tip sizes as a function of barista presence and payment method).

\section{Feelings towards tip screens and tip jars}

Results from a paired samples t-test showed that, according to the frequentist analysis, participants had significantly greater negative feelings towards establishments that utilize tip screens compared to those that utilize tip jars $\left(M_{d}=-0.47\right.$, $95 \%$ CI $[-0.91,-0.02], t(59)=-2.10, p=.040, \mathrm{BF}_{10}=$ 1.08 , Cohen's $d=0.29$; Figure 5a). However, the Bayes factor did not provide sufficient evidence for a difference between feelings toward tip screens and tip jars. Additionally, participants did not avoid establishments that utilize tip screens more frequently compared to those that utilize tip jars $\left(M_{d}=-0.12\right.$, $95 \%$ CI $[-0.54,0.31], t(59)=-0.55, p=.585, \mathrm{BF}_{10}=0.16$, Cohen's $d=0.08$; Figure 5b).

\section{Effect of payment method and barista presence on tip- ping behavior}

Since participants experienced only one tipping scenario, we used linear models to test the effects of payment method and barista presence on tip size. There were neither significant effects of payment type $(F(2,57)=0.07, p=.936$, $\left.\mathrm{BF}_{10}=0.14\right)$ nor barista presence $(F(1,58)=0.18, p=.671$, $\mathrm{BF}_{10}=0.28$ ) on tip size, suggesting that payment type (Figure 6a) and barista presence (Figure 6b) did not affect tip size. Though the frequentist analysis did not show a significant interaction effect between payment type and barista presence $\left(F(5,54)=2.08, p=.083, \mathrm{BF}_{10}=4.89\right)$, the Bayes factor suggested moderate evidence for such an interaction effect. Results from a $3 \times 2$ between subjects ANOVA supported our linear modeling analyses (see Table S8 for detailed results).

\section{Effect of empathy on barista presence}

We tested the effect of empathy on barista presence by conducting a linear model analysis. Our results yielded that empathy did not moderate the effect of barista presence on tip size, $F(3,56)=1.56, p=.210, \mathrm{BF}_{10}=0.35$ (Figure 7). In contrast, the frequentist analysis showed that empathy level alone moderated tip size, though the Bayes factor suggested more evidence is needed to support this result, $F(1,58)=4.70$, $p=.034, \mathrm{BF}_{10}=1.82$.

\section{Discussion}

The present study aimed to replicate the results obtained in Study 1 using a between-subjects design in which participants only experienced a single tipping condition. Though we replicated the Study 1 findings that participants indicated greater negative feelings towards establishments that utilize tip screens, payment method did not influence tip size, and empathy did not moderate the effect of barista presence on tipping behavior, we failed to replicate the findings that participants avoided establishments that utilize tip screens more than those that utilize tip jars, and that the presence of a barista significantly increased tip sizes. Importantly, our results from 
(a)

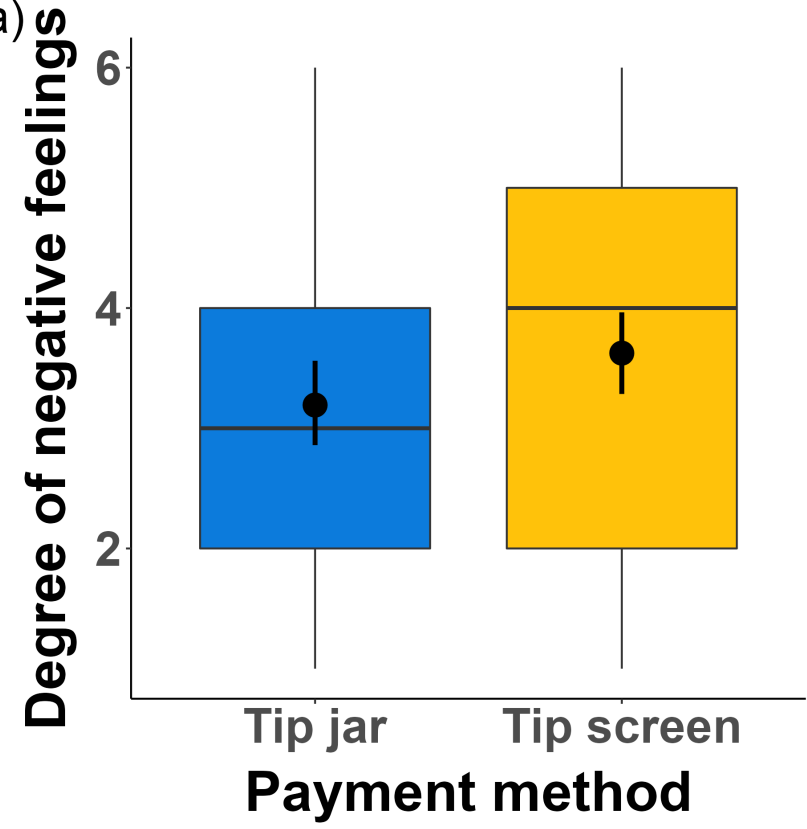

(b)

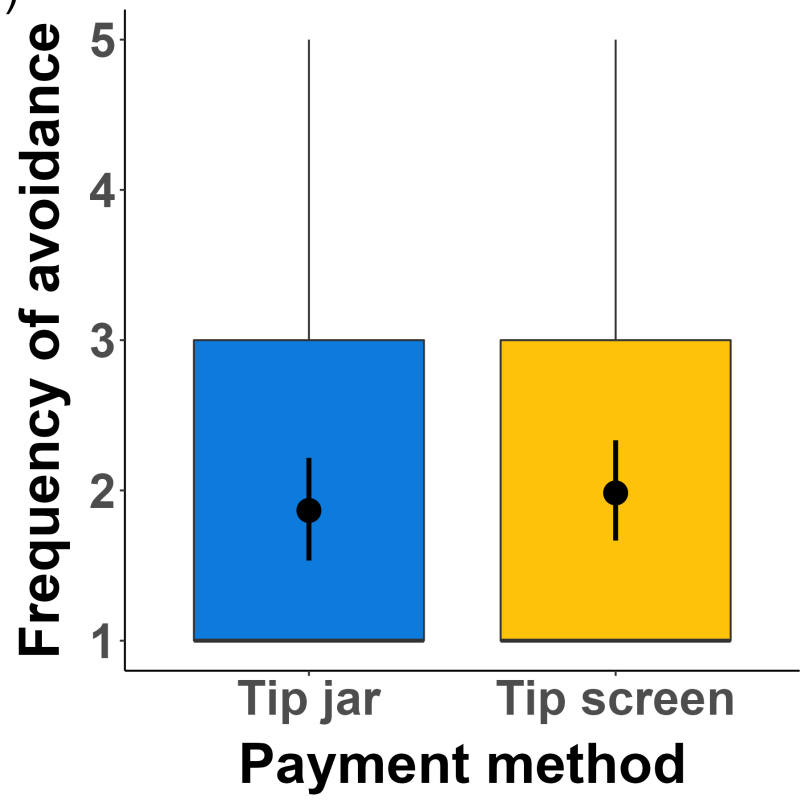

Figure 5. (a) Degree of negative feelings participants have towards establishments that utilize tip screens and tip jars in Study 2. (b) Frequency of participant avoidance of establishments that utilize tip screens and tip jars in Study 2. Frequency ratings are as follows: 1 = "never," 2 = "once," 3 = "2-5 times," 4 = "6-10 times," and 5 = "more than 10 times." Dots and error bars represent mean values and $95 \%$ between-subject confidence intervals respectively. For boxplots, horizontal bars represent medians, boxes represent interquartile ranges $\left(25^{\text {th }}-75^{\text {th }}\right.$ percentile), whiskers represent 1.5 times the interquartile range. Outliers are not shown..

(a)

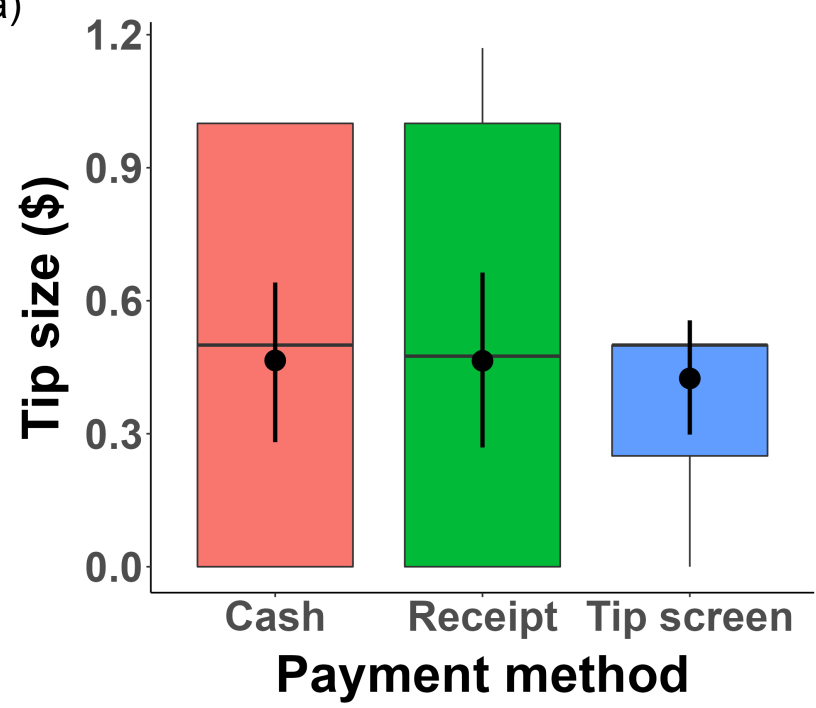

(b)

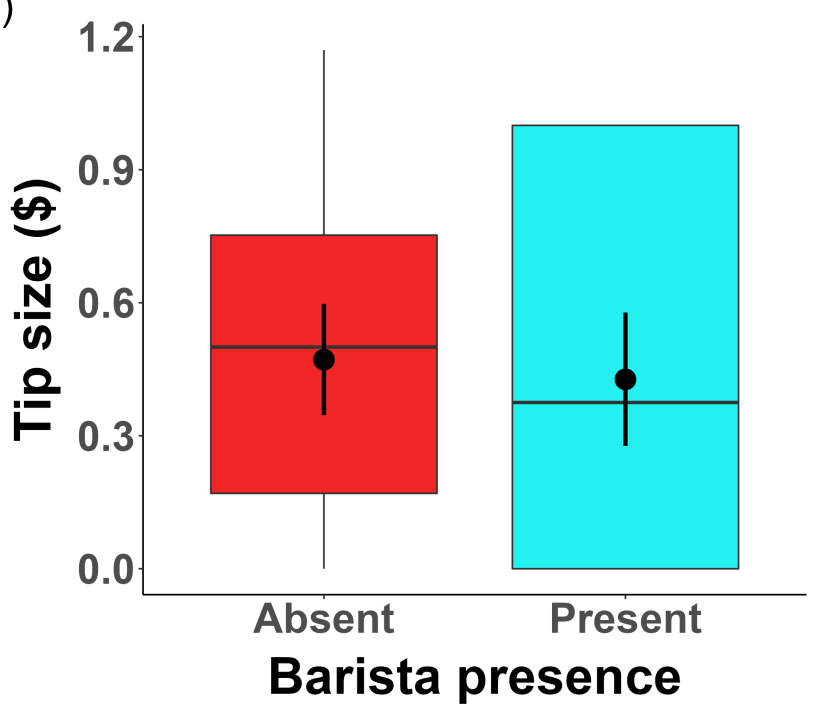

Figure 6. (a) Tip sizes indicated by participants for cash, receipt, and tip screen payment methods in Study 2. (b) Tip sizes indicated by participants for the barista absent and barista present conditions in Study 2. Dots and error bars represent mean values and $95 \%$ between-subject confidence intervals respectively. For boxplots, horizontal bars represent medians, boxes represent interquartile ranges $\left(25^{\text {th }}-75^{\text {th }}\right.$ percentile), whiskers represent 1.5 times the interquartile range. Outliers are not shown.. 


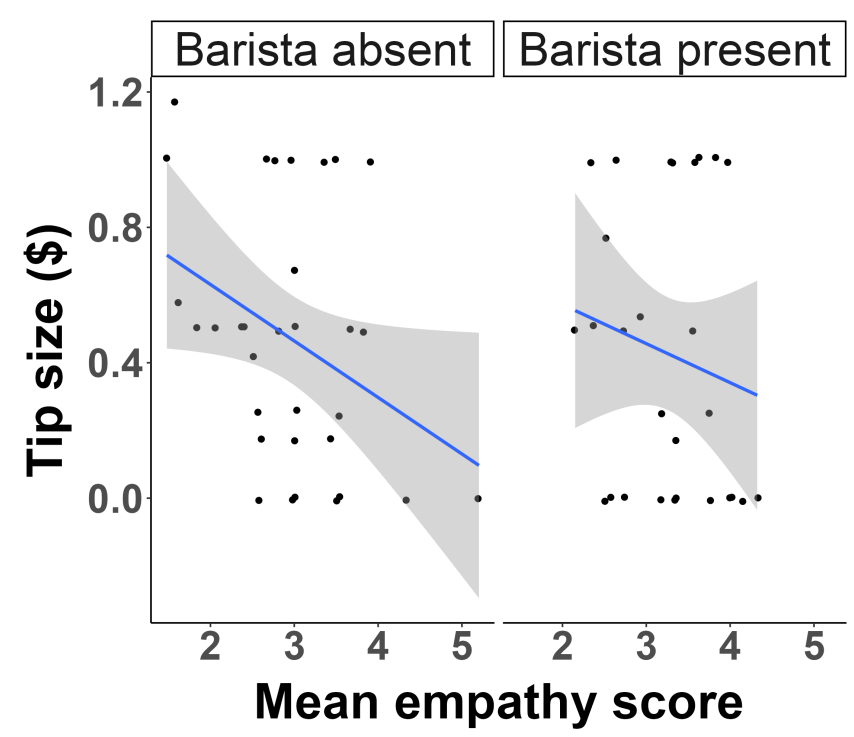

Figure 7. Tip sizes indicated by participants for the barista absent and barista present conditions across empathy scores in Study 2 (higher scores mean more empathy)..

the present study suggest that the effect of barista presence on tip size was likely a consequence of the demand characteristics of the within-subjects design of Study 1 and that the mere presence of a server alone is insufficient in eliciting larger tip sizes. However, this study showed that participants indicated more negative feelings towards establishments that utilize tip screens compared to establishments that do not, which replicates Study 1's suggestion that tip screens can cause customers to feel negatively about the consumer experience.

\section{General Discussion}

The present research examined the effects of payment method on tipping behavior. Across two studies, we found that participants indicated greater negative feelings towards establishments that use tip screens compared to those that use tip jars. Yet, payment method and barista presence did not influence tip size, suggesting that the provision of recommended tip amounts and the mere presence of a server were insufficient in nudging participants to leave larger tips. Additionally, individual empathy level did not moderate this effect on tipping behavior. Taken together, the present research extends knowledge on how tip screens can affect consumers' feelings towards establishments that utilize this payment method and how neither payment type nor presence of a server are sole determining factors of tip size.

Our findings contribute to literature on tipping in a limitedservice context by suggesting that though tip screens elicit significantly greater negative feelings in people compared to tip jars, payment method does not affect tip size when tips are solicited before service is rendered. Results from two studies showed participants expressed greater negative feelings towards (Studies 1 and 2) and avoidance of (Study 1) establishments that utilize tip screens compared to tip jars support research showing that people feel negatively toward tip requests solicited via tip screens (Karabas et al., 2020; Warren et al., 2020) and tip to avoid feeling negative emotions (Parrett, 2006; Lynn, 2009; Azar, 2010; Futrell, 2015). Though preliminary research has suggested that tip screens may lead to smaller tips for servers (Karabas et al., 2020; Warren et al., 2020), it is worth noting that these studies tested their hypotheses on tipping behavior using only a tip screen payment method whereas the present research investigated the effect of a tip screen payment method on tip size by comparing it to receipt and cash payment methods. Moreover, our finding that a tip screen payment method did not cause participants to leave larger tips compared to credit card and cash payment methods supports previous research that found no effect of payment method on tip size (Parrett, 2006; Bechkoff, 2019; Bluvstein Netter \& Raghubir, 2021). When considered together, the findings that tip screens evoke increased negative feelings in people while having no effect on tip size suggest that a tip screen payment method may motivate people to tip solely for the purpose of adhering to internalized tipping norms and not for other reasons even in the context of limitedservice establishments.

One reason why payment method did not influence tip size could have been due to the hypothetical nature of the present study. Participants could either not have given the spending situation serious consideration since they were not actually spending any money when deciding how much they had to tip, or not have experienced the pressure to tip that is perhaps felt more tangibly in real-life transactions. Future researchers should consider replicating the present study in an actual limited-service establishment to affirm this conclusion. Additionally, though the present research revealed that participants harbored more negative feelings towards establishments that utilize tip screens compared to those that utilize tip jars, a limitation of this finding was that we did not pinpoint the specific negative emotions felt by participants. Future replications of the present study should explicitly ask participants to rate the extent of specific negative emotions (e.g., guilt, shame, and irritation) felt towards tip screens and tip jars. Doing so would allow for a better understanding of people's feelings towards establishments that utilize a tip screen payment method and how these feelings may in turn affect tipping behavior.

Another reason for the lack of tip size differences across payment methods could have been due to the nature of the service environment. Most studies on tipping behavior have been discussed in the context of establishments that provide full table service where customers interact with their server over a prolonged period. The present study, on the other hand, provided participants with scenarios that featured limited service 
where customers typically have much shorter interactions with their server. Thus, the difference in customer-server interaction duration could have influenced the perception of the quality and subsequent evaluation of this interaction, eventually affecting the decision on how much to tip the server. Though more recent tipping literature has started to examine how customers' perception of service quality differs between full and limited services (e.g., Karabas et al., 2020), additional research would aid in understanding this difference better and contribute to the tipping literature where studies have found that tip sizes increase with higher service quality ratings (e.g., Lynn \& McCall, 2000; Azar, 2010; Saunders \& Lynn, 2010).

Apart from payment method, the present research also found that the presence of a barista did not increase tip sizes compared to when a barista was absent. Additionally, individual empathy levels did not moderate this effect of perceived observation on generosity, as more empathetic participants did not leave larger tips compared to their less empathetic counterparts. Taken together, these findings suggest that participants were motivated to tip to comply with social norms to tip and gain social approval instead of the motivation to supplement server wages. Furthermore, the null effect of empathy on tip sizes contrasts previous research that found empathy increased tip sizes (e.g., Parrett, 2011; Lynn et al., 2012; Lynn, 2015b; Davis et al., 2017). A possible explanation for the discrepancy in empathy effects on tip sizes could be the manner in which empathy was measured across the different studies. For instance, Parrett (2011) and Lynn et al. (2012) operationalized empathy by having their survey respondents indicate whether they had previous work experience as a server, where an affirmative response was taken to indicate increased selfperceived similarity between the respondent and their server and therefore empathy. Meanwhile, Lynn (2015b) studied the effects of empathy on tipping behavior by having participants answer statements that reflected altruistic motives (e.g., "I tip to help servers.") while Davis and colleagues (2017) actively induced empathy by having participants read a vignette prior to measuring their tipping behavior. In comparison to these studies, the present research sought to measure empathy using a validated empathy scale that comprises the components of cognitive empathy, emotional empathy, and social skills (Lawrence et al., 2004). Since empathy has not been examined using a consistent measure across studies investigating empathy effects on tipping behavior, future research should delineate between the general trait of empathy and tippingspecific concepts of empathy.

Tipping is a social custom that will persist for time to come. Understanding how bill payment methods affect tipping behavior through customer motivations to tip could be beneficial to establishments that wish to continuously provide customers with satisfactory consumer experiences. The present research aimed to contribute to this knowledge by examining how the utilization of a tip screen payment method affected tip size in a limited-service context. Though the presence of tip screens caused people to feel greater negative feelings towards, and potentially avoid, limited-service establishments that utilize this payment method, tip screens did not cause people to leave larger tips compared to more traditional modes of payment (i.e., cash and receipt). Moreover, the presence of a server did not influence tip size, affirming previous research that found people tip to comply with the social norm to do so. Taken together, our findings suggest that while tip screens may dissuade people from patronizing limited-service establishments, its presence will unlikely affect tip size. While customer compliance with the social norm to tip may generate tips for servers at the moment of purchase, it remains to be seen how the negative feelings experienced by customers due to pressure to tip will affect tipping behavior in the long-term.

\section{References}

Andraszewicz, S., Scheibehenne, B., Rieskamp, J., Grasman, R., Verhagen, J., \& Wagenmakers, E.-J. (2015). An introduction to Bayesian hypothesis testing for management research. Journal of Management, 41(2), 521-543. https://doi.org/10.1177/0149206314560412

Azar, O. H. (2007a). Why pay extra? Tipping and the importance of social norms and feelings in economic theory. The Journal of SocioEconomics, 36(2), 250-265. https://doi.org/10.1016/j.socec.2005.1 1.046

Azar, O. H. (2004). What sustains social norms and how they evolve?: The case of tipping. Journal of Economic Behavior $\mathcal{E}$ Organization, 54(1), 49-64. https://doi.org/10.1016/j.jebo.2003.06.001

Azar, O. H. (2007b). Do people tip strategically, to improve future service? Theory and evidence. Canadian Journal of Economics, 40(2), 515-527. https://doi.org/10.1111/j.1365-2966.2007.00419.x

Azar, O. H. (2010). Tipping motivations and behavior in the U.S. And Israel. Journal of Applied Social Psychology, 40(2), 421-457. https: //doi.org/10.1111/j.1559-1816.2009.00581.x

Bates, D., Mächler, M., Bolker, B., \& Walker, S. (2015). Fitting linear mixed-effects models using lme4. Journal of Statistical Software, 67(1), 1-48. https://doi.org/10.18637/jss.v067.i01

Bateson, M., Nettle, D., \& Roberts, G. (2006). Cues of being watched enhance cooperation in a real-world setting. Biology Letters, 2(3), 412-414. https://doi.org/10.1098/rsbl.2006.0509

Bechkoff, J. (2019). Digital tipping intimidation at the counter. Association of Marketing Theory and Practice Proceedings 2019. https: //digitalcommons.georgiasouthern.edu/amtp-proceedings_2019/55

Bluvstein Netter, S., \& Raghubir, P. (2021). Tip to show off: Impression management motivations increase consumers' generosity. Journal of the Association for Consumer Research, 6(1). https: //doi.org/10.1086/710239

Bodvarsson, Ö. B., \& Gibson, W. A. (1997). Economics and restaurant gratuities: Determining tip rates. American Journal of Economics and Sociology, 56(2), 187-203. https://doi.org/10.1111/j.15367150.1997.tb03460.x

Burnham, T. C., \& Hare, B. (2007). Engineering human cooperation: Does involuntary neural activation increase public goods contributions? Human Nature, 18(2), 88-108. https://doi.org/10.1007/s121 10-007-9012-2

Conlin, M., Lynn, M., \& O’Donoghue, T. (2003). The norm of restaurant tipping. Journal of Economic Behavior E Organization, 52(3), 297321. https://doi.org/10.1016/S0167-2681(03)00030-1

Davis, C., Jiang, L., Williams, P., Drolet, A., \& Gibbs, B. J. (2017). Predisposing customers to be more satisfied by inducing empathy 
in them. Cornell Hospitality Quarterly, 58(3), 229-239. https: //doi.org/10.1177/1938965517704373

Deutsch, M., \& Gerard, H. B. (1955). A study of normative and informational social influences upon individual judgment. The Jour nal of Abnormal and Social Psychology, 51(3), 629-636. https: //doi.org/10.1037/h0046408

Fox, J., \& Weisberg, S. (2019). An $R$ companion to applied regression (Third). Sage. https://socialsciences.mcmaster.ca/jfox/Books/Comp anion/

Futrell, G. D. (2015). Reciprocity as an antecedent of restaurant tipping A look at gratitude and obligation. American Journal of Tourism Research, 4(2), 44-51. https://doi.org/10.11634/216837861504549

Groen, Y., Fuermaier, A. B. M., Den Heijer, A. E., Tucha, O., \& Althaus, M. (2015). The empathy and systemizing quotient: The psychometric properties of the Dutch version and a review of the cross-cultural stability. Journal of Autism and Developmental Disorders, 45(9), 2848-2864. https://doi.org/10.1007/s10803-015-2448-z

Guéguen, N., \& Jacob, C. (2014). Clothing color and tipping: Gentlemen patrons give more tips to waitresses with red clothes. Jour nal of Hospitality $\mathcal{E}$ Tourism Research, 38(2), 275-280. https: //doi.org/10.1177/1096348012442546

Guéguen, N., \& Jacob, C. (2012). Lipstick and tipping behavior: When red lipstick enhance waitresses tips. International Journal of Hospitality Management, 31(4), 1333-1335. https://doi.org/10.1016/j.ij hm.2012.03.012

Haley, K. J., \& Fessler, D. M. T. (2005). Nobody's watching?: Subtle cues affect generosity in an anonymous economic game. Evolution and Human Behavior, 26(3), 245-256. https://doi.org/10.1016/j.ev olhumbehav.2005.01.002

Iacoboni, M. (2009). Imitation, empathy, and mirror neurons. Annual Review of Psychology, 60(1), 653-670. https://doi.org/10.1146/an nurev.psych.60.110707.163604

Jacob, C., Guéguen, N., Ardiccioni, R., \& Sénémeaud, C. (2013). Exposure to altruism quotes and tipping behavior in a restaurant. Inter national Journal of Hospitality Management, 32, 299-301. https: //doi.org/10.1016/j.ijhm.2012.03.003

Jacob, C., Guéguen, N., \& Boulbry, G. (2010). Effects of songs with prosocial lyrics on tipping behavior in a restaurant. International Journal of Hospitality Management, 29(4), 761-763. https://doi.or $\mathrm{g} / 10.1016 / \mathrm{j} . \mathrm{ijhm} .2010 .02 .004$

Karabas, I., Orlowski, M., \& Lefebvre, S. (2020). What am I tipping you for? Customer response to tipping requests at limited-service restaurants. International Journal of Contemporary Hospitality Management, 32(5), 2007-2026. https://doi.org/10.1108/IJCHM-12-20190981

Kim, E. K. (2018). Has "guilt tipping" gone too far? The etiquette on when to say no. TODAY.com. https://www.today.com/money/guilttipping-are-square-mobile-payments-making-us-tip-everyonet126151

Komsta, L., \& Novomestky, F. (2015). Moments: Moments, cumulants, skewness, kurtosis and related tests. https://CRAN.R-project.org/pa ckage $=$ moments

Lawrence, E. J., Shaw, P., Baker, D., Baron-Cohen, S., \& David, A. S (2004). Measuring empathy: Reliability and validity of the Empathy Quotient. Psychological Medicine, 34(5), 911-920. https: //doi.org/10.1017/S0033291703001624

Lee, N. Y., Noble, S. M., \& Biswas, D. (2018). Hey big spender! A golden (color) atmospheric effect on tipping behavior. Journal of the Academy of Marketing Science, 46(2), 317-337. https://doi.org/10.1 007/s11747-016-0508-3

Levitz, J. (2018). You want $20 \%$ for handing me a muffin? The awkward etiquette of iPad tipping. Wall Street Journal. https://www.wsj.co $\mathrm{m} /$ articles/you-want-20-for-handing-me-a-muffin-the-awkwardetiquette-of-ipad-tipping- 1539790018

Lynn, M. (2011). Race differences in tipping: Testing the role of norm familiarity. Cornell Hospitality Quarterly, 52(1), 73-80. https: //doi.org/10.1177/1938965510389297
Lynn, M. (2015a). Service gratuities and tipping: A motivational framework. Journal of Economic Psychology, 46, 74-88. https://doi.org/ 10.1016/j.joep.2014.12.002

Lynn, M. (2015b). Explanations of service gratuities and tipping: Evidence from individual differences in tipping motivations and tendencies. Journal of Behavioral and Experimental Economics, 55, 65-71. https://doi.org/10.1016/j.socec.2015.01.002

Lynn, M. (2019). Predictors of occupational differences in tipping. International Journal of Hospitality Management, 81, 221-228. https: //doi.org/10.1016/j.ijhm.2019.04.025

Lynn, M. (2009). Individual differences in self-attributed motives for tipping: Antecedents, consequences, and implications. International Journal of Hospitality Management, 28(3), 432-438. https: //doi.org/10.1016/j.ijhm.2008.10.009

Lynn, M., \& Grassman, A. (1990). Restaurant tipping: An examination of three "rational" explanations. Journal of Economic Psychology, 11(2), 169-181. https://doi.org/10.1016/0167-4870(90)90002-Q

Lynn, M., Jabbour, P., \& Kim, W. G. (2012). Who uses tips as a reward for service and when? An examination of potential moderators of the service-tipping relationship. Journal of Economic Psychology, 33(1), 90-103. https://doi.org/10.1016/j.joep.2011.09.009

Lynn, M., \& Latané, B. (1984). The psychology of restaurant tipping. Journal of Applied Social Psychology, 14(6), 549-561. https: //doi.org/10.1111/j.1559-1816.1984.tb02259.x

Lynn, M., \& McCall, M. (2000). Gratitude and gratuity: A meta-analysis of research on the service-tipping relationship. The Journal of SocioEconomics, 29(2), 203-214. https://doi.org/10.1016/S10535357(00)00062-7

Lynn, M., \& McCall, M. (2016). Beyond gratitude and gratuity: A meta-analytic review of the predictors of restaurant tipping. http: //scholarship.sha.cornell.edu/workingpapers/21

Lynn, M., \& Mynier, K. (1993). Effect of server posture on restaurant tipping. Journal of Applied Social Psychology, 23(8), 678-685. https://doi.org/10.1111/j.1559-1816.1993.tb01109.x

Lynn, M., Zinkhan, G. M., \& Harris, J. (1993). Consumer tipping: A cross-country study. Journal of Consumer Research, 20(3), 478488. https://doi.org/10.1086/209363

McCall, M., \& Belmont, H. J. (1996). Credit card insignia and restaurant tipping: Evidence for an associative link. Journal of Applied Psychology, 81(5), 609-613. https://doi.org/10.1037/00219010.81.5.609

Morey, R. D., \& Rouder, J. N. (2018). BayesFactor: Computation of bayes factors for common designs. https://CRAN.R-project.org/pa ckage $=$ BayesFactor

Morey, R. D., Rouder, J. N., Jamil, T., Urbanek, S., Forner, K., \& Ly, A. (2018). BayesFactor: Computation of Bayes factors for common designs. https://CRAN.R-project.org/package=BayesFactor

Müller, K. (2017). Here: A simpler way to find your files. https: //CRAN.R-project.org/package=here

Navarro, D. (2015). Learning statistics with $r$ : A tutorial for psychology students and other beginners. (Version 0.5). University of Adelaide. http://ua.edu.au/ccs/teaching/lsr

Parrett, M. (2011). Do people with food service experience tip better? The Journal of Socio-Economics, 40(5), 464-471. https: //doi.org/10.1016/j.socec.2010.09.006

Parrett, M. (2006). An analysis of the determinants of tipping behavior: A laboratory experiment and evidence from restaurant tipping. Southern Economic Journal, 73(2), 489-514. https://doi.org/10.2307/20 111903

Pedersen, T. L. (2019). Patchwork: The composer of plots. https: //CRAN.R-project.org/package= patchwork

Peugh, J. L. (2010). A practical guide to multilevel modeling. Journal of School Psychology, 48(1), 85-112. https://doi.org/10.1016/j.jsp.20 09.09 .002 
R Core Team. (2020). R: A language and environment for statistical computing. R Foundation for Statistical Computing. https://www.Rproject.org/

Ratcliff, R. (1993). Methods for dealing with reaction time outliers. Psychological Bulletin, 114(3), 510-532. https://doi.org/10.1037/00332909.114.3.510

Robinson, D., \& Hayes, A. (2020). Broom: Convert statistical analysis objects into tidy tibbles. https://CRAN.R-project.org/package=broo

Rouder, J. N. (2014). Optional stopping: No problem for Bayesians. Psychonomic Bulletin $\mathcal{E}$ Review, 21(2), 301-308. https://doi.org/10.375 8/s13423-014-0595-4

Saunders, S. G., \& Lynn, M. (2010). Why tip? An empirical test of motivations for tipping car guards. Journal of Economic Psychology, 31(1), 106-113. https://doi.org/10.1016/j.joep.2009.11.007

Schönbrodt, F. D., \& Wagenmakers, E.-J. (2018). Bayes factor design analysis: Planning for compelling evidence. Psychonomic Bulletin $\mathcal{E}$ Review, 25(1), 128-142. https://doi.org/10.3758/s13423-017$1230-\mathrm{y}$

Shih, I.-H., Jai, T.-M. C., Chen, H. S., \& Blum, S. (2019). Greetings from Emily! The effects of personalized greeting cards on tipping of hotel room attendants. International Journal of Contemporary Hospitality Management, 31(8), 3058-3076. https://doi.org/10.1108/IJCHM05-2018-0398

Stoffel, M. A., Nakagawa, S., \& Schielzeth, H. (2017). rptR: Repeatability estimation and variance decomposition by generalized linear mixedeffects models. Methods in Ecology and Evolution, 8, 1639???1644. https://doi.org/10.1111/2041-210X.12797

Taylor, E. (2016). Mobile payment technologies in retail: A review of potential benefits and risks. International Journal of Retail $\mathcal{E}$ Distribution Management, 44(2), 159-177. https://doi.org/10.1108/IJRDM05-2015-0065
Waal, F. B. M. de. (2008). Putting the altruism back into altruism: The evolution of empathy. Annual Review of Psychology, 59(1), 279300. https://doi.org/10.1146/annurev.psych.59.103006.093625

Wagenmakers, E.-J. (2007). A practical solution to the pervasive problems of p values. Psychonomic Bulletin E Review, 14(5), 779-804. https://doi.org/https://doi.org/10.3758/BF03194105

Wagenmakers, E.-J., Love, J., Marsman, M., Jamil, T., Ly, A., Verhagen, J., Selker, R., Gronau, Q. F., Dropmann, D., Boutin, B., Meerhoff, F., Knight, P., Raj, A., Kesteren, E.-J. van, Doorn, J. van, Šmíra, M., Epskamp, S., Etz, A., Matzke, D., ... Morey, R. D. (2018). Bayesian inference for psychology. Part II: Example applications with JASP. Psychonomic Bulletin $\mathcal{E}$ Review, 25(1), 58-76. https://doi.org/10.3758/s13423-017-1323-7

Wagenmakers, E.-J., Morey, R. D., \& Lee, M. D. (2016). Bayesian benefits for the pragmatic researcher. Current Directions in Psychological Science, 25(3), 169-176. https://doi.org/10.1177/096372141664 3289

Warren, N., Hanson, S., \& Yuan, H. (2020). Feeling manipulated: How tip request sequence impacts customers and service providers? Journal of Service Research, 1-18. https://doi.org/10.1177/109467051990 0553

Whaley, J. E., Douglas, A. C., \& O'Neill, M. A. (2014). What's in a tip? The creation and refinement of a restaurant-tipping motivations scale: A consumer perspective. International Journal of Hospitality Management, 37, 121-130. https://doi.org/10.1016/j.ijhm.2013.11 .005

Wickham, H., Averick, M., Bryan, J., Chang, W., McGowan, L. D., François, R., Grolemund, G., Hayes, A., Henry, L., Hester, J., Kuhn, M., Pedersen, T. L., Miller, E., Bache, S. M., Müller, K., Ooms, J., Robinson, D., Seidel, D. P., Spinu, V., ... Yutani, H. (2019). Welcome to the tidyverse. Journal of Open Source Software, 4(43), 1686. https://doi.org/10.21105/joss.01686 